\title{
Developing physical activity interventions for children with a visual impairment: Lessons from the First Steps initiative
}

Jennifer B. Scally

Rhiannon Lord

Scally, J.B. and Lord, R., Developing physical activity interventions for children with a visual impairment: Lessons from the First Steps initiative, British Journal of Visual Impairment.

Copyright @ [2019] (The Author(s)). Reprinted by permission of SAGE Publications.

DOI for the published version of the Contribution on the SAGE Journals website: 10.1177/0264619618823822 


\title{
Developing physical activity interventions for children with a visual impairment: Lessons from the First Steps initiative
}

\author{
Jennifer B. Scally (Corresponding author) ${ }^{1}$ \\ Division of Sport and Exercise Sciences, Abertay University, Dundee, UK \\ Rhiannon Lord
}

Social Sciences of Physical Activity, Sport and Exercise (SSPASE), Division of Sport and Exercise Sciences, Abertay University, Dundee, UK

\begin{abstract}
Children with a visual impairment are less active than their sighted peers. Yet they are born with the potential to match their sighted peers' motor skill competency and levels of physical fitness.

Environmental barriers are one of the main causes of inequities. This paper provides insight on these issues, drawing upon a physical activity intervention called 'First Steps', a British Blind Sport initiative that aimed to get more children with a visual impairment more active.

Physical activity packs were delivered to 53 children aged 5-15 years old with a visual impairment. Of these participants, $62 \%$ had additional impairments or medical conditions. A mixed-methods approach was used to gather participants' experiences of physical activity prior to receiving this pack and canvas opinion on how the pack changed their activity levels.

The findings revealed inequitable experiences of physical activity. The First Steps pack made considerable progress in developing children's physical activity levels. Participants' motor skills, social interactions and confidence improved. Organisations working with this population might look to adopt a similar concept. Recommendations for those wishing to do so are provided.
\end{abstract}

Keywords: Physical activity; visual impairment; children; intervention; mixed-methods

\footnotetext{
${ }^{1}$ Jennifer B. Scally (Corresponding author). Division of Sport and Exercise Sciences, Abertay University, Bell Street, Dundee, DD1 1HG. Email: jenniferbscally@gmail.com
} 


\section{Introduction}

Physical activity provides psychosocial and physiological health benefits for children and adolescents (Biddle \& Asare, 2011). Yet, there are increasing concerns that this population does not meet the World Health Organisation (WHO) recommendation of 60 minutes of moderate to vigorous physical activity daily (WHO, 2018), including children with a visual impairment (Augestad \& Jiang, 2015; Haegele \& Porretta, 2015). Kozub and Oh (2004), for example, found that their sample of 19 students with a visual impairment (aged 6-18 years old) spent on average less than 28 minutes per day undertaking moderate to vigorous physical activity. Further, Engel-Yeger and Hamed-Daher (2013) found that children with a visual impairment (aged 6-12 years old) were involved in fewer activities, at a lower intensity, than their sighted peers.

Children with a visual impairment are reported to have reduced motor skill competency and health related fitness in comparison to their sighted peers (Haibach, Wagner \& Lieberman, 2014; Haegele, Brian \& Goodway, 2015; Lieberman \& McHugh, 2001; Lieberman et al. 2013; Wagner, Haibach \& Lieberman, 2013). Visual impairment can significantly affect individuals' balance, posture and coordination; all of which can be improved with increasing physical activity (Bouchard \& Tétreault, 2000). Research has shown that the energy requirements associated with daily living increase with level of visual impairment due to reduced efficiency of movement patterns (Kobberling, Jankowski \& Leger, 1989). Lower levels of health-related fitness and motor skill competency associated with reduced levels of physical activity can result in reduced autonomy and less independent navigation in daily living (Skaggs \& Hopper, 1996). 
However, children with a visual impairment have the potential to sustain healthy levels of physical fitness and motor skill competency, matching that of their sighted peers (Haegele \& Porretta, 2015). School-age children with visual impairments have described physical activity as enjoyable and fun (Ward, Fansworth, Babkes-Stellino \& Perrett, 2011). Those who take part in physical activity in educational settings are more likely to engage in extracurricular sport (Ponchillia, Strause, \& Ponchillia, 2002). However, as they go through life, children with a visual impairment tend to take part in less physical activity, thus it is particularly important that they become physically active in childhood to sustain a prolonged healthy, active lifestyle (Kozub \& Oh, 2004). Positive experiences of physical activity in childhood carried out by someone who understands how to adapt activities appropriately and use modified equipment are more likely to lead to sustained healthy physical activity later in life (Lieberman \& McHugh, 2001; Lieberman et al. 2013).

\section{Barriers to participation}

Most barriers to physical activity in children with a visual impairment are environmental rather than genetic. Lower levels of health-related fitness and motor skill development in children with a visual impairment have been associated with inequitable opportunities to take part in physical activity and sport (Haegele, Brian \& Goodway, 2015; Lieberman et al. 2010). Children with a visual impairment have been demonstrated to have low levels of physical activity (Haegele \& Porretta, 2015). A lack of knowledge by instructors on how to adapt lessons and use modified equipment has been reported to reduce opportunities for children with a visual impairment (Haibach et al. 2014; Stuart, Lieberman \& Hand, 2006). Studies have shown that teachers feel ill-equipped to sufficiently adapt physical education lessons for their students and fear for the child's safety (Lieberman \& Houston-Wilson, 1999). Linked to 
this, fear of injury is the most frequently cited barrier to participation stated by parents of children who are blind (Stuart et al. 2006). Moreover, the most common barriers stated by children with a visual impairment include being unaware of what activities to participate in, being unsure of what to do, having nobody to do activities with and being mocked by peers (Dane-Staples, Lieberman, Ratcliff \& Rounds, 2013; DeSchipper, Lieberman and Moody, 2017).

\section{Physical activity interventions}

Despite increasing evidence of inequitable physical activity opportunities for children with a visual impairment, there have been few intervention studies in the past 30 years (Furtado, Allums-Featherston, Lieberman \& Gutierrez, 2015; Haegele \& Porretta, 2015). Only one intervention study has examined the impact of providing parents with resources regarding physical activity and sport specifically for children with a visual impairment (Robinson \& Lieberman, 2007). This was the only study implemented within a home-setting (Furtado, Allums-Featherston, Lieberman \& Gutierrez, 2015). Yet, those studies that have been carried out suggest that interventions, or modifications to existing programs, have been successful in raising physical activity levels (Cervantes \& Poretta, 2013; Ponchillia, Armbruster \& Wiebold, 2005). Subsequently, there have been increasing calls for intervention studies (Furtado et al. 2015; Haegele \& Porretta, 2015). Thus, the purpose of this study was to conduct an intervention with children who have a visual impairment (including those with additional impairments or medical conditions). Within this aim, there were two underlying objectives. First, to gain an understanding of their experiences of physical activity and sport 
and assess its effectiveness in increasing their physical activity levels and developing motor skills. Second, to report on the effectiveness of the intervention to inform future work.

\section{Methods}

\section{The 'First Steps' initiative}

"First Steps" was a British Blind Sport project aiming to provide an initial physical activity opportunity to children aged 5-15 years old with a visual impairment. It provided children (and their families) with a free physical activity pack that they could play with at home. This pack was designed to develop their motor skills, health-related fitness and self-efficacy toward physical activity and sport in a safe environment.

A small pilot project in the West Midlands, England was carried out, scoping participants' initial reactions to the initiative. Following this, a more developed initiative was undertaken targeting children with a visual impairment across Scotland. A research team gathered data on individuals' physical activity patterns before and after receiving the First Steps pack as well as their feedback on the pack itself. In order to contextualise these physical activity patterns, the researchers utilised the initial questionnaire to investigate the participation of children with a visual impairment in physical activity and sport in Scotland. The experiences of children with a visual impairment in physical activity and sport naturally emerged in focus groups and interviews. The researchers have included this data to add context to findings and enable comparisons in pre- and post-pack activity. This paper reports on the evaluative findings of the Scottish-based project.

\section{Participants}


To recruit participants, the project was advertised on the British Blind Sport webpage. It was also promoted by partnership organisations whose aims and objectives aligned with the initiative (e.g. Scottish Disability Sport, Blind Children UK, RNIB Scotland). Potential participants were asked to go to the Wufoo webpage (an online platform for creating and hosting surveys) and register for their free activity pack. Applications were also accepted via telephone to reduce the barriers to participation associated with impairment. During this registration process, participants were asked to provide personal data (e.g., age, sex, postal address for the pack to be delivered) and information about their current physical activity levels thus forming phase 1 of data collection, the pre-pack survey (see below). At this point, they could also opt in to further data collection attempts.

The initiative's inclusion criteria were children aged 5-15 years old, who had a parentreported visual impairment, lived in Scotland (verified by postal address), and that had the capacity to improve health related fitness or motor skill competency.

If a child was deemed inactive by their parent/guardian, they automatically received a pack. In instances where applications were received for parent perceived physically active children, telephone conversations took place between experienced British Blind Sport staff and parents/guardians to ascertain whether the child would benefit from a First Steps pack. In instances where children had the potential to develop their motor skill competency or were not meeting the recommended amount of physical activity, a pack was provided.

Fifty-three participants with a visual impairment aged 5-15 years old and their families took part in the study (Table 1.). To enable grouping and based on common terminology utilised by health professionals and related charities in the United Kingdom; children were asked to 
highlight if they were partially sighted or had a severe sight impairment. Additional impairments were parent-reported. There was a large variance in additional impairments which prevented a comparative analysis between children with or without additional impairments. Children with additional impairments accounted for $62.3 \%$ of all participants. However, they accounted for $73.3 \%$ of children who were physically inactive and $66.7 \%$ of children whose only physical activity was school-based ${ }^{2}$. Parents who elaborated on their child's additional impairments primarily stated that their child had a physical impairment $(n=13)$ or a learning disability $(n=12)$ or both $(n=8)$. The most frequent type of physical impairment was cerebral palsy $(\mathrm{n}=11)$. Less frequently stated impairments or medical conditions included hearing impairments $(n=3)$, albinism $(n=2)$, epilepsy $(n=3)$ and autism $(n=4)$. Parents defined their child(ren) as physically active $(n=38)$ or physically inactive $(n=15)$. Of those defined as active, the only provisions they were receiving were offered by their school and were mainly swimming $(n=1)$ or $P E(n=5)$. All of these participants took part in the first phase of the study, an initial pre-pack survey. Sixteen participants and their parents responded to the post-pack survey. Their demographic information is in Table 1.

Table 1. Participant information

\begin{tabular}{|l|l|l|l|}
\hline & $\begin{array}{l}\text { Study } \\
\text { participants }\end{array}$ & $\begin{array}{l}\text { Post-pack survey } \\
\text { participants } \\
\mathrm{n}(\%)\end{array}$ & $\begin{array}{l}\text { Focus group } \\
\text { participants } \\
\mathrm{n}(\%)\end{array}$ \\
\hline $\begin{array}{l}\text { Gender } \\
\text { Female } \\
\text { Male }\end{array}$ & $27(51)$ & $\begin{array}{l}9(56) \\
7(44)\end{array}$ & $\begin{array}{l}4(50) \\
4(50)\end{array}$ \\
\hline Age & $26(49)$ & $9.44 \pm 2.87$ & $8.75 \pm 2.92$ \\
\hline $\begin{array}{l}\text { Level of Visual Impairment } \\
\text { Partially Sighted }\end{array}$ & $10.17 \pm 3.07$ & $13(81)$ & $6(75)$ \\
Severely Sight Impaired & $38(72)$ & $3(19)$ & $2(25)$ \\
\hline $\begin{array}{l}\text { Type of Visual Impairment } \\
\text { Congenital } \\
\text { Acquired }\end{array}$ & $15(18)$ & $11(69)$ & $5(62.5)$ \\
\hline
\end{tabular}

${ }^{2}$ Inclusive of children with multiple disabilities and visual impairment (MDVI). 


\begin{tabular}{|l|l|l|l|}
\hline Additional Impairments & & & \\
Yes & $33(62)$ & $10(63)$ & $4(50)$ \\
No & $20(38)$ & $6(37)$ & $4(50)$ \\
\hline School & & $13(81)$ & $5(62.5)$ \\
Mainstream & $47(89)$ & $3(19)$ & $3(37.5)$ \\
Specialist & $6(11)$ & & \\
\hline
\end{tabular}

For the final phase of the study, eight participants aged 5-13 years old and their families took part in focus groups to provide rich, detailed data on their survey responses. Participants were selected using a maximum variation sampling strategy (Sparkes \& Smith, 2014) to ensure a cross-section of opinions and feedback on the First Steps pack were represented. Variation was based on age, gender, geographical location, impairment type (congenital or acquired), additional impairment(s) and educational context. See Table 2.

Table 2. Focus group participants information

\begin{tabular}{|l|l|l|l|l|l|}
\hline $\begin{array}{l}\text { Child's } \\
\text { Pseudonym } \\
\text { (Parent's } \\
\text { pseudonym) }\end{array}$ & Age & Gender & $\begin{array}{l}\text { Partially } \\
\text { Sighted / } \\
\text { Severely } \\
\text { Sight } \\
\text { Impaired }\end{array}$ & $\begin{array}{l}\text { Additional } \\
\text { impairment(s)/medical } \\
\text { condition(s) }\end{array}$ & $\begin{array}{l}\text { Educational } \\
\text { context }\end{array}$ \\
\hline $\begin{array}{l}\text { Cameron } \\
\text { (Lucy) }\end{array}$ & 7 & Male & $\begin{array}{l}\text { Partially } \\
\text { Sighted }\end{array}$ & No & Mainstream \\
\hline $\begin{array}{l}\text { Rebecca } \\
\text { (Lesley) }\end{array}$ & 8 & Female & $\begin{array}{l}\text { Partially } \\
\text { Sighted }\end{array}$ & No & Mainstream \\
\hline $\begin{array}{l}\text { Polly } \\
\text { (Sally) }\end{array}$ & 6 & Female & $\begin{array}{l}\text { Partially } \\
\text { Sighted }\end{array}$ & $\begin{array}{l}\text { Cerebral Palsy \& } \\
\text { Global Development } \\
\text { Delay }\end{array}$ & Specialist \\
\hline $\begin{array}{l}\text { Ella } \\
\text { (Paula) }\end{array}$ & 10 & Female & $\begin{array}{l}\text { Partially } \\
\text { Sighted }\end{array}$ & 'Extended Tummy' & Mainstream \\
\hline
\end{tabular}




\begin{tabular}{|l|l|l|l|l|l|}
\hline $\begin{array}{l}\text { Kevin } \\
\text { (Luke) }\end{array}$ & 13 & Male & $\begin{array}{l}\text { Partially } \\
\text { Sighted }\end{array}$ & Cerebral Palsy & Specialist \\
\hline $\begin{array}{l}\text { Harriet } \\
\text { (Natalie) }\end{array}$ & 7 & Female & $\begin{array}{l}\text { Partially } \\
\text { Sighted }\end{array}$ & No & Mainstream \\
\hline $\begin{array}{l}\text { Finn } \\
\text { (Theresa) }\end{array}$ & 5 & Male & $\begin{array}{l}\text { Severely } \\
\text { Sight } \\
\text { Impaired }\end{array}$ & No & $\begin{array}{l}\text { Mainstream } \\
\text { (unit for } \\
\text { visual } \\
\text { impairment) }\end{array}$ \\
\hline $\begin{array}{l}\text { Lauren } \\
\text { (Gail) }\end{array}$ & 12 & Female & $\begin{array}{l}\text { Severely } \\
\text { Sight } \\
\text { Impaired }\end{array}$ & $\begin{array}{l}\text { Cerebral Palsy \& } \\
\text { Learning Disability }\end{array}$ & Specialist \\
\hline
\end{tabular}

\section{The First Steps Activity Pack}

The free First Steps activity pack was sent to all participants who met the inclusion criteria and registered their details on the First Steps webpage. Each pack contained:

- 'Jangles', a red jingle ball $(21 \mathrm{~cm})$

- A pump

- An activities booklet

- A reward chart

- Stickers

- A British Blind Sport balloon

The activities booklet provided participants and their parents' guidance on what types of activities they could do with the pack contents (as suggested by Stuart et al. 2006). It contained fundamental motor skills presented as activities designed to repeat basic movements (recommended by Haibach et al. 2014). Skills included kicking, underarm roll 
and chest pass. Activities were presented as a story of Jangles, the jingle ball, journeying through various challenges to different locations. Text and images were made as accessible by restricting the colour palette to high contrast colours, using font size 16 and using simplistic designs without fine detail. The stickers and reward chart were designed to engage children with the activities in the booklet. Stickers provided in the pack included a variation of eyes, noses and mouths that could be added to the jingle ball to increase personalisation of the Jangles character.

\section{Procedures}

Full ethical approval was granted for the study. A mixed-methods research design was implemented in four phases (Figure 1.). The lead author was the Project Coordinator for First Steps Scotland, and therefore in employment with British Blind Sport at the time of research. As part of this role, she led all phases of the research. This utilised online surveys, one prior to the intervention and one post intervention, and, following the post-pack survey, focus groups to capture detailed opinion and rich data on these patterns.

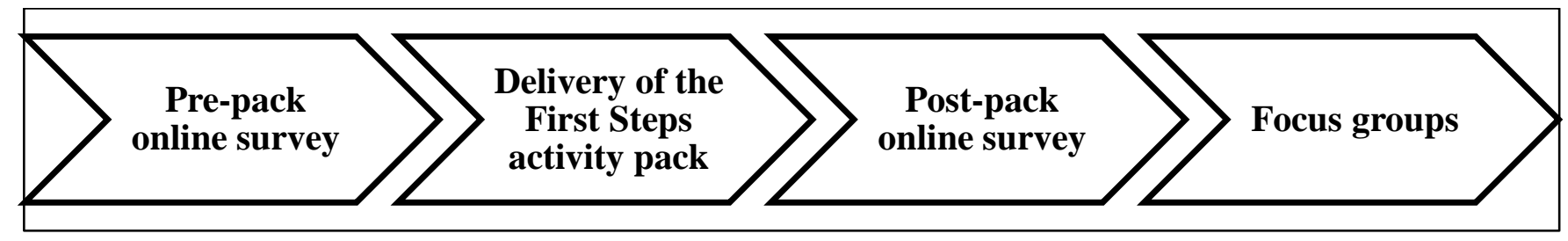

Figure 1. Four phase research design.

Phase one: Online survey software, Wufoo, was used to construct an initial survey. This survey was divided into two parts. First, initial questions asked potential participants to provide personal data to establish their eligibility for a free Frist Steps activity pack, 
according to the initiative's inclusion criteria. Specifically, the child's age, visual impairment, additional impairments or medical conditions and their postcode (to ascertain a location and delivery address for the pack) were collected. This section also included questions about their preferred contact method and the level of involvement they wanted in the study, specifically which phases of the research they wanted to take part in, if at all. Some general information about children's lives was also captured at this point (e.g., educational context). The second part of the survey asked participants (and their parents) questions about their physical activity levels and ideas about sport and exercise. These questions were created using existing literature on physical activity in children with a visual impairment as a basis. These questionnaires were developed specifically to evaluate this intervention and were reviewed by British Blind Sport to establish face validity for the cohort. Some questions required answers to be recorded on a Likert scale, others provided open questions to allow participants more freedom to give their thoughts. Due to the nature of the task and the relatively young age or the additional impairments of some of the participants, parents were explicitly asked in instructions to complete the survey in collaboration with their child. Thus, many of the questions were worded for parents, but the responses should reflect the opinions of the child and their parent/guardian. There were 53 respondents and all agreed to take part in this phase (see Table 1).

Phase Two: On completion of the initial survey and confirmation of participant eligibility, a free First Steps pack was sent to participants' homes via post. The physical activity pack was designed to fit through a standard UK mailbox to minimise inconvenience to participants and maximise receipt of the pack. All packs were received by participants who registered in phase 1. 
Phase Three: After a three-week period, participants (and their parents) were contacted via email to give feedback on their First Steps pack. To do so, participants were asked to complete a post-pack survey also constructed using Wufoo. Participants were asked openended and Likert scale questions about the First Steps pack they received and how they felt it had changed their physical activity levels, if at all. Again, if the person completing the survey was a parent or guardian, they were instructed to complete this section with their child and consult them where appropriate to form a response. There were 16 respondents in this phase (see Table 1.).

Phase Four: Families were contacted via their preferred contact method and asked if they were still willing to take part in a focus group. If they agreed, an appointment for the focus group was made with the lead researcher. It was made clear that both the child and at least one parent/guardian must be present at the focus group. Other family members (e.g., siblings), particularly those who had engaged in the pack, were welcome to join in the discussion. An interview schedule, based on patterns observed within survey data, was used to guide open discussion about the First Steps pack and how this had changed the children's/families' physical activity levels and/or ideas about sport and exercise. Focus groups lasted between 20 minutes and 51 minutes and were recorded using a dictaphone. All focus groups were transcribed verbatim.

Multiple mechanisms were put in place at the design and data collection stages of this research to ensure the trustworthiness of data. That is, its credibility, transferability, dependability and confirmability (Sparkes and Smith, 2014). For example, to ensure survey data met these criteria, both researchers and British Blind Sport reviewed survey questions. They checked for coherence and word choices to ensure questions were not 
misleading or ambiguous. Researchers then designed the interview schedule for focus groups based on survey responses to allow patterns of responses to be discussed and deconstructed. During the focus groups, the lead researcher, who had prolonged and practical experience supporting children with a disability to participate in physical activity and sport, asked questions in different ways so that corroboration could be made across the same participant's responses. During the final analysis process, both researchers reviewed the data and themes to ensure the final analytical tale was trustworthy.

\section{Data analysis}

The frequency of closed and Likert question data from the surveys was calculated in percentages for patterns to be identified and discussed. Open questions within the survey data were qualitatively analysed, using a hierarchal content analysis (as defined by Sparkes \& Smith, 2014). Codes were generated from responses and discussed across the research team as part of the inter-rater reliability process. These codes were then systematically identified across data sets and the frequency of their appearance noted. Tables were then produced illustrating the hierarchal ranking of this code.

Focus group data was thematically analysed, drawing upon Braun and Clark's (2006) sixstage framework - immersion, generating initial codes, searching for and identifying themes, reviewing themes, defining and names themes and writing the report. Based on this framework, first, the research team immersed themselves in the data by (re)reading focus group transcripts. Second, a list of initial codes were generated from the immersive process. Third, from the codes identified, themes were produced by refocusing the analysis to a broader level. That is, sorting codes into groups to form possible themes based on the 
research aim. This means recognising commonalities or threads of meaning across transcripts. From this process, three themes were identified - Initial experiences of physical activity and everyday life, experiences of the First Steps pack and constructive feedback on the First Steps pack. We searched for these themes across the transcripts and collated extracts of the data that were relevant to each code and/or theme. Fourth, the themes were reviewed at two different levels. An initial review took place by (re)reading the collated extracts in relation to each theme and considering if a coherent pattern of meaning was being established. Then, a latter review of the themes in relation to the entire data set took place. In this case, we incorporated the survey data into this process and found there was a coherence between the focus group themes and survey findings. On this basis, and in the fifth step, we named themes to enable a reader establish what the essence of the theme is. Ultimately, the three themes that emerged from the overarching review of data were - 'Initial experiences of physical activity and sport', 'Benefits of the initiative' and 'Constructive feedback on the First Steps pack'. Finally, through written reporting processes, the themes have been embedded within an analytic tale that provides an interpretation of the data.

\section{Results and Discussion}

Three main themes were developed and identified across the datasets whilst answering the study's main aims. The themes were named 'Initial experiences of physical activity and sport', 'Benefits of the initiative' and 'Constructive feedback on the First Steps pack'. These have been used to structure the findings.

\section{Initial experiences of physical activity and sport}


This research has revealed new insights on children with a visual impairment's experiences of physical activity and sport. Initial survey data illustrated mixed opinions on and experiences of participants' physical activity (Figure 2.). 


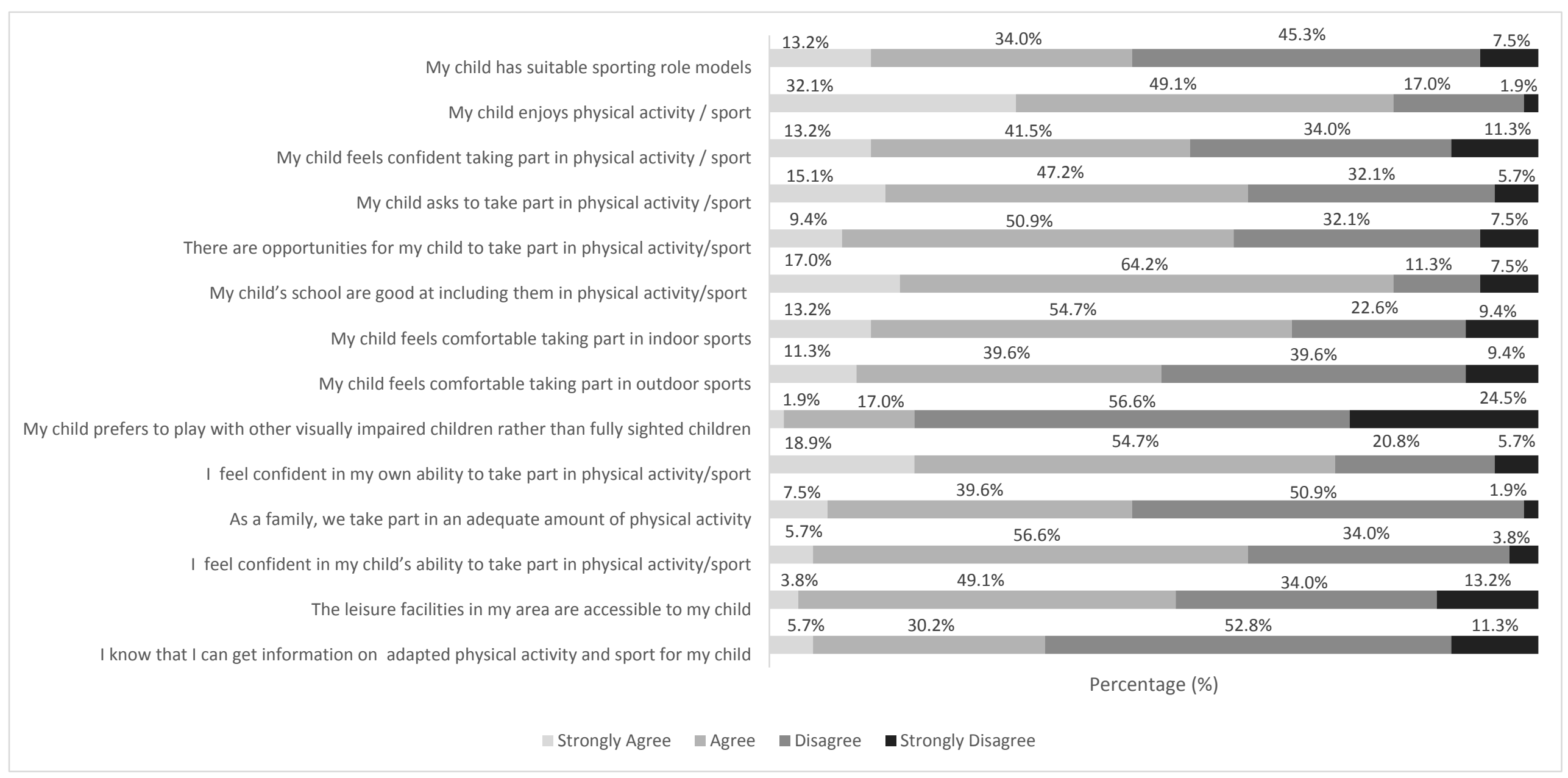

Figure 2. Initial experiences of physical activity and sport. 
Most participants and their families were positive about their opportunities for and experiences of physical activity and sport. Like Ward et al.'s (2011) study, most respondents stated that their child enjoyed sport and physical activity $(81.2 \%)$ and asked to take part (62.3\%). Most parents reported to be confident about their child's ability to take part in physical activity and sport (62.3\%), as well as their own abilities (73.6\%), although indoor settings were preferable to outdoor settings. Many children also reported that they felt confident taking part in physical activity and/or sport (54.7\%). Participants mainly stated there were opportunities to take part in physical activity $(60.3 \%)$ and leisure facilities were accessible (52.9\%). Further, schools were inclusive of the child's needs $(81.2 \%)$ and inclusive participation, with sighted peers was preferable $(81.1 \%)$.

However, despite these general patterns, many participants still reported negatively on these elements (Figure 2.), revealing inequalities and potential discrimination. For example, $47.2 \%$ of participants felt local leisure facilities were not accessible for their child and $37.8 \%$ of respondents felt there were limited opportunities for their child to take part in sport and/or physical activity, providing further evidence of inequitable experiences for children with a visual impairment, particularly in comparison to their sighted peers (Engel-Yeger \& HamedDaher, 2013). This is concerning, given legislative demands for more equitable opportunities for disabled people (e.g., The Equality Act, 2010) and financial and developmental commitment to disability sport as part of the London 2012 (UK Government, 2015) and Glasgow 2014 legacies (Legacy 2014, 2014). Moreover, most respondents acknowledged their family did not engage in enough physical activity or sport (52.8\%) and they did not know where to find information on suitable forms of activity (64.1\%), supporting Stuart et al.'s (2006) work. There were also few suitable role models for their child(ren) (52.8\%). Thus, the findings support claims that people with a visual impairment are one of the most 
sedentary populations (Engel-Yeger and Hamed-Daher, 2013). Indeed, 44 of the 53

participants stated their child experienced barriers to participation (Table 3.).

Table 3. Perceived barriers to participation in physical activity

\begin{tabular}{|l|l|}
\hline Barrier & Frequency \\
\hline Physical impairment & 13 \\
\hline No perceived barriers & 9 \\
\hline Visual Impairment & 8 \\
\hline Lack of confidence & 8 \\
\hline Lack of understanding of teachers and coaches & 5 \\
\hline Lack of coordination & 5 \\
\hline Fear of Injury & 5 \\
\hline Comparison to or Interactions with Sighted Peers & 5 \\
\hline Catering for children with multiple disabilities and visual impairment (MDVI) & 4 \\
\hline Poor Ball Control Skills & 3 \\
\hline Lack of balance & 2 \\
\hline Epilepsy & 2 \\
\hline Timing of activities & 1 \\
\hline Sun Exposure & 1 \\
\hline Need for adapted equipment & 1 \\
\hline Learning Disability & 1 \\
\hline Hearing Impairment & 1 \\
\hline Financial Cost & 1 \\
\hline Awareness of clubs for children with a visual impairment & 1 \\
\hline Accessibility of facilities & 1 \\
\hline
\end{tabular}

Within the focus groups, participants and their parents elaborated on their barriers to participation. Despite $81.1 \%$ of participants disagreeing with the statement "my child prefers to play with other visually impaired children rather than fully sighted children" in the initial survey (Figure 2), there were examples where children stated they had experienced reprimands for bumping into other children because of their visual impairment.

There was one time, my old teacher for PE, I think it was like Mrs Smith, when we were doing a running thing I bumped into people, and then the people said it was on purpose and then I got something like a detention. (Cameron)

Reprimands clearly had an impact on children's motivations to take part in physical activity. For example, one parent, Rebecca's mother said: 
... she was telling me she was sick, she didn't want to go and I said why do you not want to go, you really really liked it? And then she just kind of let out, "how would you like it if you bumped into somebody and they told on you".

Participation alongside sighted peers was noted as a barrier to participation, but bullying-like behaviours noted in DeSchipper et al.’s (2017) study were not explicitly cited. Instead variations in spatial awareness and physicality were highlighted as barriers to regular and sustained physical activity. For example, Brian's mother stated in the initial survey, 'He cannot keep up with sighted peers; he gets frustrated'. Also, David's mother stated in the initial survey, 'He can't see kids moving fast, so is scared in case he is knocked over'.

In addition, like Lieberman et al.'s (2002) study, there was evidence that participants' felt some instructors, particularly those outside the school environment, failed to understand how to adapt sessions for children with a visual impairment. Harry's mother stated in the initial survey 'I find it hard to find groups who understand his needs and can tailor activities to suit him'. Yet, $81.2 \%$ of parents felt that their child's school were good at including them in physical activity and sport (Figure 2). Focus group evidence suggested that teachers had received training on how to support the needs of participants with a visual impairment. For example, Rebecca's mother stated 'before she went in to school, all the teachers got a kind of workshop on it anyway. Erm so they all kind of know [how to lead activities for children with a visual impairment]'. Conroy (2012) found that the teachers interviewed sought and required information regarding how to adapt physical activity for children with a visual impairment. The present study implies that in instances where teachers are provided with additional training, this can promote promising experiences for the children involved. Physical education within schools is an important platform for children with a visual impairment's long-term engagement in physical activity and sport (Ponchillia et al. 2002). 
Like Lieberman and Houston-Wilson's (1999) findings, participants cited a lack of confidence as a key barrier to participation. For example, Rebecca's mother stated 'It was too busy she couldn't really see what she was doing which knocked her confidence'. Improving children's feelings of confidence of motor skill competency is of the utmost importance to remove this barrier (Brian et al. 2018). This also reinforces the knowledge held by physical activity practitioners to split children into smaller group in order to support a child with a visual impairment to better thrive. Enabling children to succeed in small tasks, be rewarded for completing them and present them with progressions in skill development are important for increasing self-efficacy and motor skill competency (Bouchard \& Tétreault, 2000).

\section{Benefits of the initiative}

The post-pack survey and focus groups highlighted several benefits of the First Steps pack. Parents noted their child(ren)'s ability and confidence to perform gross motor skills improved, particularly throwing $(68.75 \%)$ and catching $(81.25 \%$, see Figure 3$)$. 


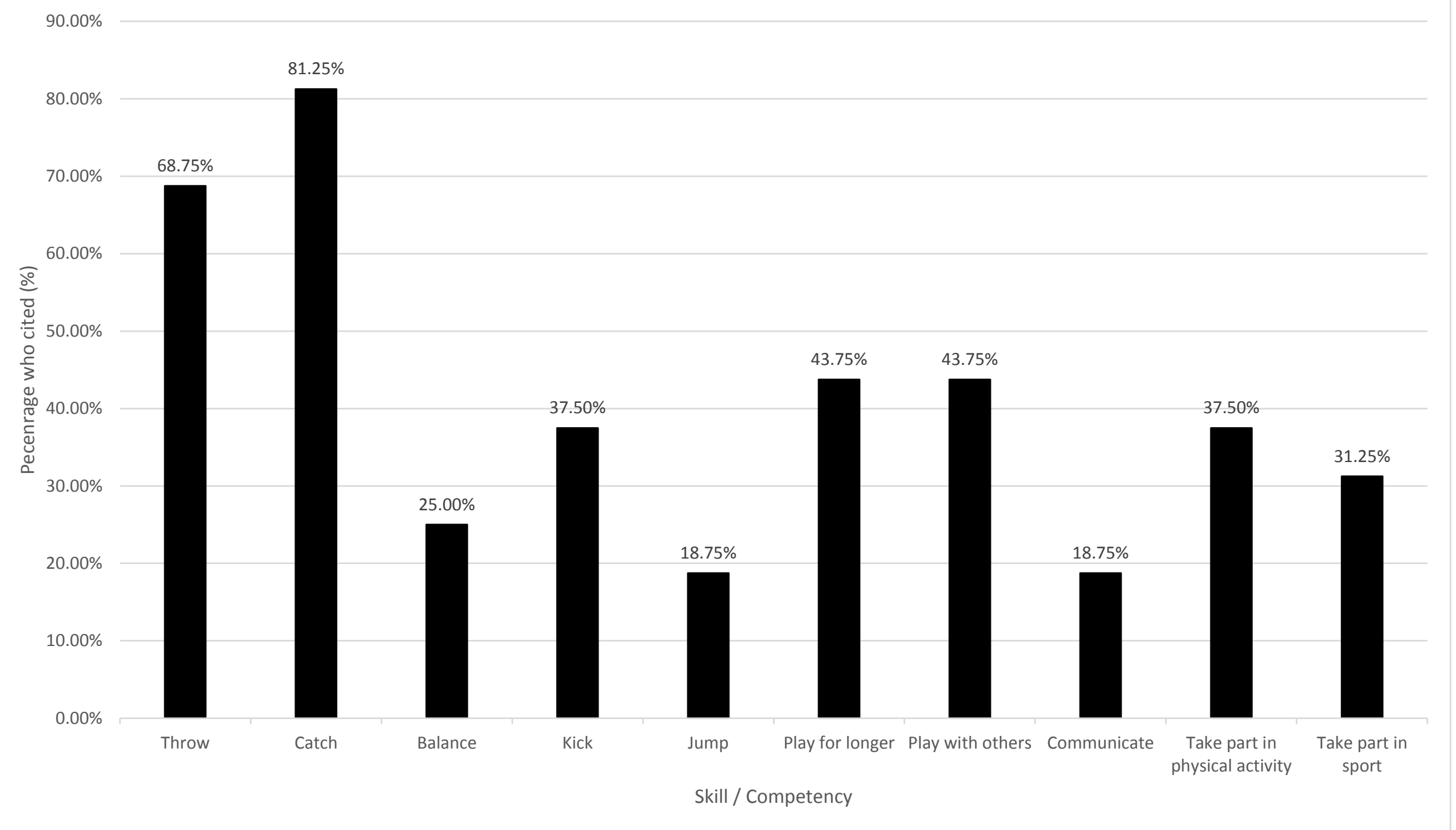

Figure 3. Perceived improvements in gross motor skills and other competencies. 
Catching skills were understandably higher because the jingle ball provided in the pack was brightly coloured and more visible to children who were partially sighted. When bounced, the ball was audible to children enabling greater opportunities to track the ball.. Increased motor skills developed children's confidence. Parents commented:

[Before] She would always say help me and we were at my mum and dads and my dad was throwing the balloon about and she caught it and we were all like, wow, no helping, and I strongly believe it was doing this, doing these activities with the ball that encouraged her and gave her that confidence that I [she] can do this.

(Polly's mother)

However, parents also felt their child(ren)'s other gross motor skills, such as throwing and kicking had improved because of engagement with the pack. For example, one post-pack survey response stated, 'Michael loves playing, throwing and catching it, skittles, and even started enjoying kicking it'.

Children's use of the First Steps pack with their grandparents, parents, siblings or friends was reported in $93.8 \%$ of the respondents. Subsequently, $43.75 \%$ of respondents felt their child(ren)'s social interactions improved as part of this initiative. Focus group discussions provided examples of how the First Steps pack had strengthened interactions with children's sighted peers. In some cases, participants took on more of a leadership role during play, demonstrating greater confidence. Engagement with the pack also led to increased physical activity levels for both the participants, their family and friends. Polly's mother stated:

I liked the fact that my niece, she got involved in it. She came for a sleepover so we explained it to her and she was really excited about it as well. So instead of sometimes where it's pretty much my niece going to Polly, like supporting her, it was then like they could do it together and that was nice to see as well.

Another parent said 'Ella enjoyed trying out all the activities within the pack but preferred to take Jangles [the jingle ball] out with a group of friends [of mixed ages] and lead the way. All the children enjoyed the experience'. These types of interactions give credence to the potential social benefits of this type of activity pack. Previous studies suggest children with a visual impairment fear or face mocking by their peers (DeSchipper et al. 2017), but this 
activity pack allowed them to engage in physical activity and lead this the activity. Thus, this concept might be extending by other groups or organisations looking to develop children with a visual impairment's independence and confidence. Further, one of the main barriers to physical activity cited for children with a visual impairment was a lack of information on what types of activity they can do and how to adapt equipment and activities and/or use adapted equipment (Haibach et al. 2014; Stuart et al. 2006). Similarly, many post-pack respondents claimed this was the first time they had been given information on how to lead physical activity for their child (81.3\%). Thus, sharing information on what types of activities children can do and how to conduct them will likely have a positive impact of their physical activity levels.

As noted in the latter quote (above), the jingle ball was central to the benefits reported by participants. The characterisation of Jangles played a key role in children and their families' engagement with this initiative. In focus groups and open-question responses on the postpack survey, participants referred to the jingle ball as 'Jangles', demonstrating a good level of 'buy in' with the character and the story in the pack. Their ability to personalise the ball with stickers provided in the pack also supported this. For example, Polly's mother said 'I wouldn't really sit and go, lets kick a ball, let's throw a ball. So, it was, we're helping Jangles, we're doing this and I think that was the difference'. Ryan's mother said in the postpack survey: 'We loved Jangles and that you could personalise him'.

Further, Jangles developed children's independent activity and confidence, because of the audibility associated with it. For example, David's mother said 'Jangles was great as he wasn't scared to catch it as he could hear it coming towards him'. One post-pack survey highlighted, 'Eilidh loved the ball. It was amazing to see her use it and be able to find it 
without someone helping'. There was a clear sense of enjoyment that came with engaging with the pack contents (Ward et al. 2011), particularly the jingle ball, for many families. Rebecca's mother said, '...it just made her happy every time'.

Linked to this, participants also took the pack contents into other environments, outside of the home (i.e., physiotherapy sessions and school). Three of the eight participants who took part in focus groups were prescribed exercises by a physiotherapist due to a physical impairment. Two of these families incorporated Jangles into these activities to make them more engaging. For example, Kevin's father stated ‘...we looked at the exercises, ay didn’t we, that's where we got the idea to incorporate Jangles in to your normal exercises, that's actually where we got the idea'.

Parents also commented on the benefits of the pack, particularly Jangles, in school playground settings. It provided children an opportunity to become more active through play, although, similar to other studies (e.g., Conroy, 2012; Lieberman et al. 1999), there was some suggestion that school staff did not fully understand the initiative. Cameron's mother, commented:

... what I noticed with [him] in the playground is there is not a lot of playground games that visually impaired kids can play at ease. Maybe just a wee sheet to put in that these are games [would have helped].

Although many participants and their families had used an adapted ball before, few families had used this equipment at home. The First Steps pack provided participants with relatively low-cost equipment they could use at home, and gave them information on how to use this with their child, thus removing barriers to physical activity cited in previous studies (e.g., Haibach et al. 2014; Stuart et al. 2006). Removal of these barriers led to increased physical activity levels, perceived improvements in gross motor skills and developments in children's 
social skills. Children and their families engaged with the characterisation and story of Jangles, leading to play-based physical activity and they could incorporate this into other more formal settings away from the home (e.g., physiotherapy and school).

\section{Constructive feedback on the First Steps pack}

In addition to the perceived benefits received, participants provided extensive feedback on the First Steps pack. Much of the constructive feedback focused on the activity booklet, stickers and rewards chart provided within the pack. Some participants felt the activities were too prescriptive and too long:

We kind of got that far [warm up] and gave up... The weather was rubbish. We didn't get outside. Em. We weren't, we weren't very committed and it's not that we haven't played with Jangles. But we maybe found that the prescriptiveness of this didn't work for us.

(Harriet's mother)

However, the same participant offered some contradictory comments indicating that they desired more prescriptiveness in the activity booklet around when to award stickers and how warm-up activities should take place:

\footnotetext{
It was a case of - well we've done that; do we get a sticker for it?...I [also] didn't know whether that was to be viewed as a, just a thing in its own right [warm up activity] and then you just go into the other sections or whether to use that as a warm up before you do any of the sections. (Hariett's mother)
}

In addition, many participants commented on the font sizes and textures of the materials in the pack, specifically the activity booklet and stickers. For example:

They [words] are too small to read umm I don't know, like myself when I get him stickers I try and make them scented stickers or ones that have got the holographic look on them so you get a shine of them or like textured ones.

(Finn's mother)

Although carefully considered at the design stage, there were limited funds to produce tactile materials and a larger font size than the minimum recommended for people with a visual impairment (font size 16) would have incurred increased printing costs. The images within 
the booklet were prioritised over the text and covered significantly more of the page. Young people with a visual impairment prefer audio-haptic stimuli (Morelli, Folmer, Foley \& Lieberman, 2011). Therefore, developers of this concept should consider reducing the size of images to permit increased font size. Tactile stickers and/or sections the booklet and reward chart and/or the addition of audio materials to accompany text and images would also likely engage children further with the pack.

Participants also commented on the inclusivity of the pack, particularly in relation to age and type of impairment. The initiative targeted a broad population - children aged 5-15 years old with a visual impairment, but participants had mixed opinions on the age-appropriateness of the activity pack. Parents felt that the packs could have benefitted younger children. Finn's mother, said, 'I think at his age right now [5 years old] it's ideal and like I said it could be quite useful for younger children as well maybe'. Some older participants' parents aged 1214 years old (with no additional impairments) felt the materials were too childish. However, the pack was suitable for some older children with additional support needs. One mother of a 14-year-old participant commented in the post-pack survey 'He really enjoyed putting a face on it and loved the name Mr Jangles'. It was also noted that all illustrations and activities within the booklet were marketed towards able-bodied children with a visual impairment. There were also no specific instructions on how to adapt activities for children with a visual and physical impairment(s). In the initial survey, $70.6 \%$ of those parents who felt they could not get information on adapted activity were parents of a child with additional impairments. Future packs should acknowledge the additional impairments or medical conditions many children with a visual impairment have, as identified in this study (Table 1.). Images of children who are wheelchair users, for example, might be included. Instructions for activities could provide a small note on how to adapt them (if adaptation is necessary) for children with 
a physical impairment. Representing the diversity of children who are likely to receive a pack is important for positive and sustained engagement.

\section{Limitations}

In addition to limitations of the First Steps pack, there were five main limitations of the study as a whole. First, many of the participants had other impairments or medical conditions in addition to a visual impairment. Thus, the barriers they faced before and during the intervention may not be solely attributed to visual impairment. It was not possible to further deconstruct data for the purpose of this paper because of the vast nature of the additional impairments and medical conditions reported. Further, most participants found out about the project through British Blind Sport key partners and were therefore already in contact with support services who actively promote physical activity for children with a visual impairment. Whilst the aim of the pack was to target children who were completely inactive, in addition to those who did not engage in recommended guidelines, reaching this population was a considerable challenge. Second, the pre/post-pack survey questions were not scientifically validated by academic experts in the field. Third, although respondents were instructed to complete the survey collaboratively with their child(ren), researchers had little control over survey completion processes as this took place in participants' homes without the researcher present. The prominence of parental voices in the focus group stage of the study also gives further credence to the limitations of these methods in capturing children with a visual impairment's voice in and through research (Haegele, Yessick \& Kirk, 2017). Fourth, this initiative aimed to increase physical activity levels and therefore other potential benefits of the pack such as increased socialisation and taking part in sport, which have been identified in the findings, were not specifically focused upon at the outset. Adaptations of the 
activity booklet should include activities involving multiple people which might aid children's socialisation. Further, an underarm roll and kicking was included within the activities booklet in order to aid sport specific skill development for Goalball and Football, for example, but the addition of further sport specific activities and links to video footage for parents might aid greater development in organised sport. Finally, this work reinforces calls for intervention-based studies, particularly those that are more longitudinal in nature. It was not within the scope of this research to monitor pack usage and therefore any further benefits or limitations of the physical activity pack after the initiative had finished, just three weeks after delivery.

\section{Concluding thoughts}

This study provided fresh insights into the experiences of children with a visual impairment and their parents. Findings of their initial experiences of physical activity and sport revealed concerning indications of inequality and potential discrimination, suggesting more developmental work is required. Much provision has been allocated to para-sport (UK Government, 2015; Legacy 2014, 2014), but more concentrated efforts are needed at grass roots level sport and physical activity for health.

The First Steps intervention, carried out by British Blind Sport, produced promising benefits for children with a visual impairment, including those with additional impairments. The pack aided the development of gross motor skills, social interactions with family and peers and increased physical activity levels through play-based activity. Some participants also incorporated the activities into their physiotherapy activities and playground activities in 
school, indicating the potential for this concept to be adopted and developed by other organisations, coach practitioners, educators and physiotherapists.

\section{References}

Augestad, L. B., \& Jiang, L. (2015). Physical activity, physical fitness, and body composition among children and young adults with visual impairments: A systematic review. British Journal of Visual Impairment, 33(3), 167-182.

Biddle, S. J., \& Asare, M. (2011). Physical activity and mental health in children and adolescents: a review of reviews. British Journal of Sports Medicine, 45 (11), 886-895.

Bouchard, D., \& Tétreault, S. (2000). The motor development of sighted children and children with moderate low vision aged 8-13. Journal of Visual Impairment and Blindness, 94 (9), 564-573.

Brian, A., Haegele, J. A., Nesbitt, D., Lieberman, L. J., Bostick, L., S. Taunton, S., \& Stodden, D. F. (2018). Perceptions of motor competence for children with and without visual impairments. Journal of Visual Impairments and Blindness, 112(1), 118-124.

Braun, V., \& Clarke, V. (2006). Using thematic analysis in psychology. Qualitative Research in Psychology, 3 (2), 77-101.

Cervantes, C. M., \& Porretta, D.L. (2013). Impact of after school programming on physical activity among adolescents with visual impairments. Adapted Physical Activity Quarterly, 30 (2), 127-146.

Conroy, P. (2012). Supporting Students with Visual Impairments in Physical Education: Needs of Physical Educators. Insight: Research and Practice in Visual Impairment and Blindness, 5 (1), 3-10.

Dane-Staples, E., Lieberman, L., Ratcliff, J., \& Rounds, K. (2013). Bullying experiences of individuals with visual impairment: The mitigating role of sport participation. Journal of Sport Behavior, 36 (4), 365-386.

DeSchipper, T., Lieberman, L. J., \& Moody, B. (2017). "Kids like me, we go lightly on the head": Experiences of children with a visual impairment on the physical self-concept. British Journal of Visual Impairment, 35(1), 55-68.

Engel-Yeger, B., \& Hamed-Daher, S. (2013). Comparing participation in out of school activities between children with visual impairments, children with hearing impairments and typical peers. Research in Developmental Disabilities, 34 (10), 3124-3132. 
Furtado, O. L., Allums-Featherston, K., Lieberman, L. J. \& Gutierrez, G. L. (2015). Physical activity interventions for children and youth with visual impairments. Adapted Physical Activity Quarterly, 32 (2), 156-176.

Haibach, P. S., Wagner, M. O. \& Lieberman, L. J. (2014). Determinants of gross motor skill performance in children with visual impairments. Research in Developmental Disabilities, $35,2577-2584$.

Haegele, J. A., Brian, A., \& Goodway, J. (2015). Fundamental motor skills and school-aged individuals with visual impairments: A review. Review Journal of Autism and Developmental Disorders, 2(3), 320-327.

Haegele, J. A., \& Porretta, D. (2015). Physical activity and school-age individuals with visual impairments: A literature review. Adapted Physical Activity Quarterly, 32 (1), 68-82.

Haegele, J.A., Yessick, A. \& Kirk, T.N. (2017) Physical activity experiences of youth with visual impairments: An Alaskan perspective. British Journal of Visual Impairment. 35(2), 103-112.

Kobberling, G., Jankowski, L. W., \& Leger, L. (1989). Energy Cost of Locomotion in Blind Adolescents. Adapted Physical Activity Quarterly, 6 (1), 58-67.

Kozub, F. M., \& Oh, H. (2004). An exploratory study of physical activity levels in children and adolescents with visual impairments. Clinical Kinesiology, 58 (3), 1-7.

Legacy 2014. (2014, August 7). Games legacy continues with £6millon investment in parasports. Retrieved from http://www.legacy2014.co.uk/legacy-in-action/games-legacycontinues-with-\%C2\%A36-million-investment-in-para-sports

Lieberman, L. J., Byrne, H., Mattern, C. O., Watt, C. A., \& Fernández-Vivó, M. (2010). Health related fitness in youth with visual impairments. Journal of Visual Impairment and Blindness, 104, 349-359.

Lieberman, L. J. \& Houston-Wilson, C. (1999). Overcoming the Barriers to Including Students With Visual Impairments and Deaf-Blindness in Physical Education. RE:view, 31 (3), 129-137.

Lieberman, L. J., Houston-Wilson, C., \& Kozub, F.M. (2002). Perceived Barriers to Including Students With Visual Impairments in General Physical Education. Adapted Physical Activity Quarterly, 19 (3), 364-377.

Lieberman, L. J. \& McHugh, E. (2001). Health-Related Fitness of Children Who Are Visually Impaired. Journal of Visual Impairment and Blindness, 95 (5), 272-287.

Lieberman, L. J., Ponchillia, P. E. \& Ponchillia, S. V. (2013). Physical Education and Sports for People with Visual Impairments and Deafblindness: Foundations of Instruction. Huntington, WV: American Foundation for the Blind Press.

Morelli, T., Folmer, E., Foley, J. T. \& Lieberman, L. J. (2011). Improving the lives of youth with visual impairments through exergames. Insight: Research and Practice in Visual 
Impairment and Blindness, 4 (4), 160-170.

Ponchillia, P.E., Armbruster, J. \& Wiebold, J. (2005). The national sports education camps project: Introducing sports skills to students with visual impairments through short-term specialized instruction. Journal of Visual Impairment and Blindness, 99 (11), 685-695.

Ponchillia, P. E., Strause, B. \& Ponchillia, S. V. (2002). Athletes with visual impairments: Attributes and sports participation. Journal of Visual Impairment and Blindness, 96 (4), 267272.

Robinson, B.L., \& Lieberman, L.J. (2007). Influence of a parent resource manual on physical activity levels of children with visual impairments. Rehabilitation Education for Blindness and Visual Impairment, 39(3), 129-140.

Skaggs, S. \& Hopper, C. (1996). Individuals with visual impairments: A review of psychomotor behaviour. Adapted Physical Activity Quarterly, 13 (1), 16-26.

Sparkes, A. C. \& Smith, B. (2014). Qualitative Research Methods in Sport, Exercise and Health: From Process to Product. Oxon: Routledge.

Stuart, M. E., Lieberman, L. J., \& Hand, K. E. (2006). Beliefs About Physical Activity Among Children Who Are Visually Impaired and Their Parents. Journal of Visual Impairment and Blindness, 100 (4), 223-234.

UK Government. (2015, May 8). 2010 to 2015 government policy: 2012 Olympic and Paralympic legacy. Retrieved from https://www.gov.uk/government/publications/2010-to2015-government-policy-2012-olympic-and-paralympic-legacy/2010-to-2015-governmentpolicy-2012-olympic-and-paralympic-legacy

Wagner, M. O., Haibach, P. S. \& Lieberman, L. J. (2013). Gross motor skill performance in children with and without visual impairments -- Research to practice. Research in Developmental Disabilities, 34 (10), 3246-3252.

Ward, S., Fansworth, C., Babkes-Stellino, M., \& Perrett, J. (2011). Parental influences and the attraction to physical activity for youths who are visually impaired at a residential day school. Journal of Visual Impairment and Blindness, 105 (8), 493-498.

World Health Organisation. (2018, March 14). Global Strategy on Diet, Physical Activity and Health: Physical Activity and Young People. Retrieved from http://www.who.int/dietphysicalactivity/factsheet_young_people/en/ 